\title{
Modeling Internal Tides and Mixing Over Ocean Ridges: HOME Analysis
}

\author{
Donald N. Slinn \\ Department of Civil and Coastal Engineering \\ University of Florida \\ Gainesville, FL 32611-6590
}

Phone: (352) 392-9537 x 1431 Fax: (352) 392-3466 E-mail: slinn@coastal.ufl.edu

Co-Principle Investigator

Murray D. Levine

College of Oceanic and Atmospheric Sciences

Oregon State University

Phone: (541) 737-3047 Fax: 541-737-2064 Email: levine@coas.oregonstate.edu

Award \#: N00014-03-1-0424

http:/www.ce.ufl.edu/people/faculty/alpha/slinn.htm

\section{LONG-TERM GOALS}

The goals of this work are to obtain a better understanding and predictive capability for the processes involved in deep ocean boundary mixing caused by interactions of the internal tide with sloping topography as functions of key environmental parameters, such as ocean topography, ambient stratification, latitude, and tidal energy.

\section{OBJECTIVES}

- demonstrate the principal mechanisms that produce tidally induced boundary mixing.

- quantify the magnitude of the mixing rates and parameterize these values into larger scale eddy diffusivities for momentum and density.

- calibrate and verify the model predictions and error bars by testing against the HOME data sets collected over the Hawaiian ridge and interpret field data in light of results from the numerical simulations.

- investigate the dependency of the mixing efficiency as a function of environmental conditions appropriate for other ocean sites.

\section{APPROACH}

The work involves theoretical development, numerical computations, and comparison with field data. Our model formulation implements a non-hydrostatic, large eddy simulation (LES), turbulent boundary layer model (Slinn and Riley, 1998) on an $f$-plane. Environmental parameters are chosen to represent conditions from the HOME site and barotropic tides are forced similar to those present during spring tides along the Hawaiian ridge. 


\section{Report Documentation Page}

Form Approved

OMB No. 0704-0188

Public reporting burden for the collection of information is estimated to average 1 hour per response, including the time for reviewing instructions, searching existing data sources, gathering and maintaining the data needed, and completing and reviewing the collection of information. Send comments regarding this burden estimate or any other aspect of this collection of information,

including suggestions for reducing this burden, to Washington Headquarters Services, Directorate for Information Operations and Reports, 1215 Jefferson Davis Highway, Suite 1204, Arlington

VA 22202-4302. Respondents should be aware that notwithstanding any other provision of law, no person shall be subject to a penalty for failing to comply with a collection of information if it

does not display a currently valid OMB control number.

1. REPORT DATE

30 SEP 2003

2. REPORT TYPE

3. DATES COVERED

00-00-2003 to 00-00-2003

4. TITLE AND SUBTITLE

Modeling Internal Tides and Mixing Over Ocean Ridges: HOME

Analysis

6. AUTHOR(S)

a. CONTRACT NUMBER

5b. GRANT NUMBER

5c. PROGRAM ELEMENT NUMBER

5d. PROJECT NUMBER

5e. TASK NUMBER

5f. WORK UNIT NUMBER

7. PERFORMING ORGANIZATION NAME(S) AND ADDRESS(ES)

Department of Civil and Coastal Engineering,,University of

8. PERFORMING ORGANIZATION

REPORT NUMBER

Florida,,Gainesville,,FL, 32611

9. SPONSORING/MONITORING AGENCY NAME(S) AND ADDRESS(ES)

10. SPONSOR/MONITOR'S ACRONYM(S)

11. SPONSOR/MONITOR'S REPORT

$\operatorname{NUMBER}(\mathrm{S})$

12. DISTRIBUTION/AVAILABILITY STATEMENT

Approved for public release; distribution unlimited

13. SUPPLEMENTARY NOTES

14. ABSTRACT

The goals of this work are to obtain a better understanding and predictive capability for the processes involved in deep ocean boundary mixing caused by interactions of the internal tide with sloping topography as functions of key environmental parameters, such as ocean topography, ambient stratification, latitude, and tidal energy.

15. SUBJECT TERMS

16. SECURITY CLASSIFICATION OF:

a. REPORT

unclassified b. ABSTRACT unclassified c. THIS PAGE unclassified
17. LIMITATION OF ABSTRACT

Same as

Report (SAR)
18. NUMBER

OF PAGES

7 19a. NAME OF

RESPONSIBLE PERSON 


\section{WORK COMPLETED}

We have completed a series of numerical simulations. Physical parameters used are taken from the field measurements at HOME, e.g., $\mathrm{N}=2.2 \times 10^{-3} \mathrm{~s}^{-1}(1.25 \mathrm{cph})$, the latitude is $21.8 \mathrm{~N}$, giving a Coriolis parameter of $2.7 \times 10^{-5} \mathrm{~s}^{-1}$, and the tidal period of the M2 tide is 12.4 hours. With our nondimensionalization, these yield a background Richardson number of 4.84 and a Rossby number of 37 . We simulate the flow for 5-10 tidal cycles to develop a statistical average of mixing during different phases. The $x$-component of the free stream velocity induced by the barotropic tide is forced in the model to satisfy $U_{\infty}=U_{M} \cos (w t)$. Results from the numerical simulations are presented, followed by an interpretation according to a simple model. Increased internal wave activity and overturning of isopycnals are evident during phases of upslope flow. The signature of internal waves propagating away from the turbulent region are also evident, but decrease significantly during phases of down slope flow. The velocity fields show deviations from the free stream velocity out to heights of approximately 0.35 ( 70 meters). These are qualitatively similar to time series observed in the HOME field data for temperature and velocity fields (not shown).

We are focusing on an idealized uniform slope, having horizontal dimensions much larger than the turbulent boundary layer thickness. Over a tidal cycle, flow external to the boundary layer may travel up and down the slope on the order of 3 kilometers (e.g., with $U_{M} \sim 20 \mathrm{~cm} / \mathrm{s}$ and a half period of 6.2 hours). The slope itself at the HOME Survey Site extends fairly uniformly for approximately $15 \mathrm{~km}$. We are modeling a domain with dimensions of $200 \mathrm{~m}$ on each side. In the simulations presented below the length scales are chosen to be $\widetilde{L}_{x}=\widetilde{L}_{y}=\widetilde{L}_{z}=200 \mathrm{~m}$ (i.e., non-dimensional lengths are $L_{x}=$ $L_{y}=L_{z}=1.0$ ). The typical turbulent boundary layer thickness we observe is on the order of $50 \mathrm{~m}$, and the larger turbulent eddies in the domain are on the order of $20 \mathrm{~m}$ in diameter. In these simulations we used a grid resolution of $129 \times 129 \times 150$ grid points ( $\sim 2.5$ million points). With the grid clustering near the boundary we resolve eddies down to approximately $1-2 \mathrm{~m}$ in diameter while smaller turbulent structures are modeled with the turbulent eddy viscosity model.

\section{RESULTS}

Two-dimensional cross sections of the non-dimensional density field on the $x-z$ plane located at $y_{o}=$ $L_{y} / 2$ during three different phases of the tide are shown in the left column of Figure 1. The second column of panels in Figure 1 presents the density field from an "end view" on an $y-z$ plane located at $x_{o}=L_{x} / 2$ at the same times. Together these panels illustrate the most significant feature observed in the simulations: strong buoyant plumes rise from the boundary layer during a certain phase of the tidal cycle that lead to vigorous turbulent mixing in the benthic boundary layer for approximately $0.3 \mathrm{~T}$ (4 hours). The third column of Figure 1 shows contours of the kinetic energy dissipation rate normalized by the kinematic viscosity and the buoyancy frequency squared $\left(\varepsilon / v N^{2}\right)$ in the same $x-z$ plane. The right-most column of Figure 1 also shows the dissipation rate from a "top-view" in an $x-y$ plane parallel to the bottom boundary located at a height $z_{o}=0.05 \mathrm{~L}_{z}$. Higher values indicate the cores of eddies, the strong shear layer at the boundary, and other coherent vortical structures. The top row of panels is shown just after a time of maximum upslope flow (i.e., $\mathrm{t} \approx 1)$ as mixing begins to develop into turbulence and the two-dimensional buoyant plumes are released from the lighter fluid near the wall. The middle row of panels is shown during a phase of strong mixing, approaching the end of the phase of up-slope flow. The bottom row of panels is taken at a time of strong stratification, during a phase of down-slope flow when mixing has ceased. 

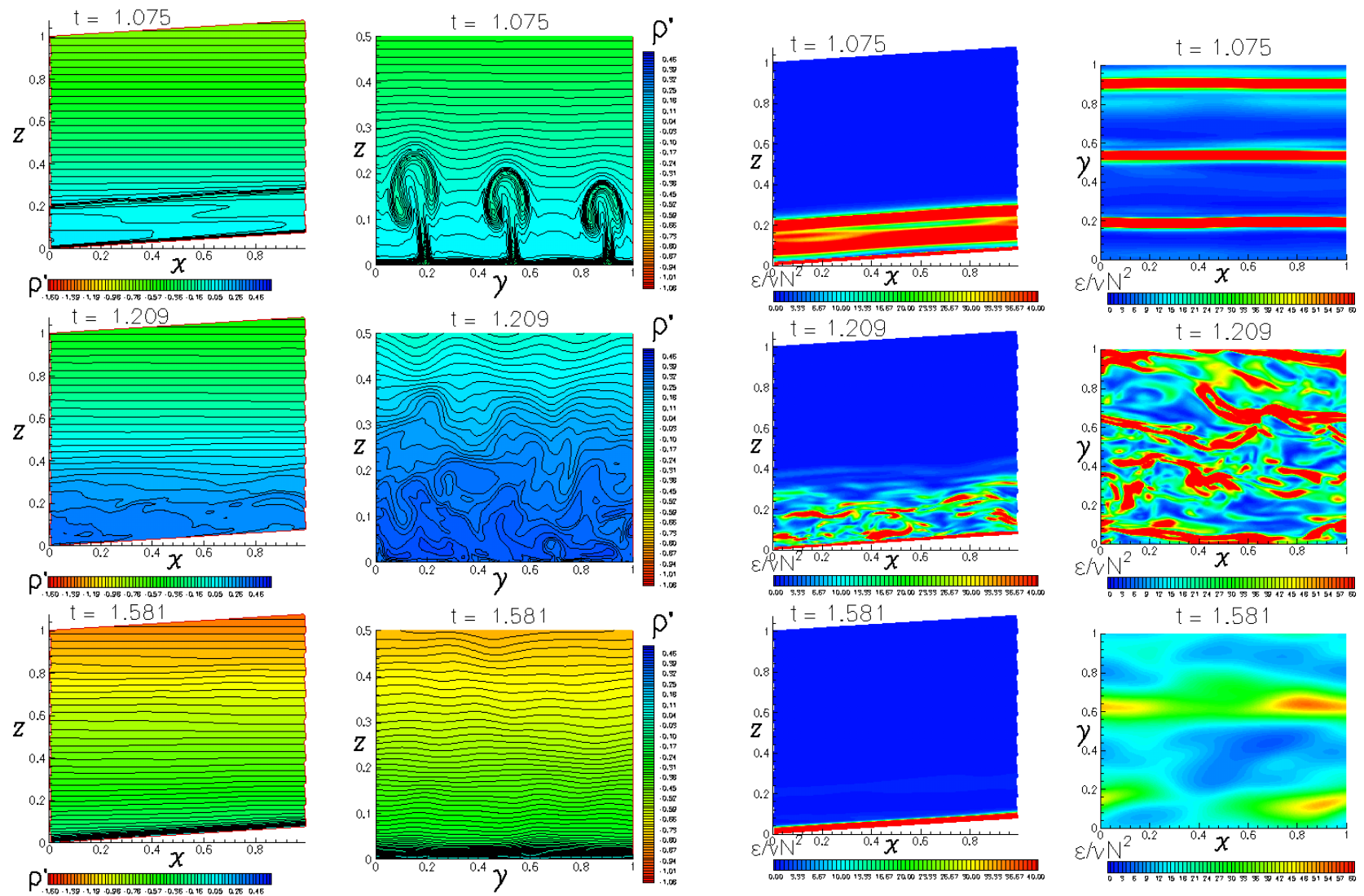

\section{Figure 1. Density fields (left) and dissipation rate contours (right) during phases of flow instability (top row), turbulent mixing (middle row) and strong stratification (bottom).}

The key physical process uncovered in the simulations is that there is a strong asymmetry during tidal phases caused by interactions between the boundary layer and the background stratification. When the flow is upslope heavier fluid is moving up from below. The fluid previously located near the wall is lighter than the fluid coming to replace it, but the friction or turbulence near the wall prevents the lighter fluid from leaving as quickly as the new heavier fluid is approaching. This leads to a situation where the lighter, slower moving fluid is retained beneath the denser water external to the boundary layer. This unstable density structure greatly enhances turbulence production near the wall. The turbulence in turn produces a thicker boundary layer of slower moving intermediate density mixed fluid. The upslope flow persists for approximately 6 hours and turbulence is particularly evident for the latter 3 hours when the flow is decelerating. The buoyancy period, external to the boundary layer, is approximately 0.8 hours, and hence, the stratified turbulence responds in a relatively short time scale compared to the duration of the flow conditions, and yet far from an instantaneous adjustment, as might be anticipated for buoyant fluid with a larger density difference. Soon after the onset of mixing the intermediate density mixed water produced in the boundary layer is also comparatively light to the deeper water still flowing upslope. The process repeats over and over during phases of upslope flow causing a quasi-steady turbulent layer with weak or unstable stratification near the boundary. We observe continuous production and release of buoyant plumes of water from the boundary layer for 
approximately 3 hours, during each cycle of upslope flow for these conditions. The turbulent layer becomes on the order of $50-80 \mathrm{~m}$ thick in these simulations.

As the flow reverses downslope, other dynamical processes become more important and the near boundary fluid containing less inertia responds to the barotropic pressure gradient first and moves down-slope while the flow exterior to the boundary layer is still directed upslope. This final phase of the mixing cycle leads to the strongest (shear induced) turbulence close to the boundary. But the turbulent layer soon collapses, because frictional forces in the boundary layer during the down-slope phase of flow have the opposite effect from the upslope phase. Now buoyancy forces act to inhibit turbulent production as lighter stratified fluid from above is moved above the denser, slower moving boundary layer water that is retarded by friction near the wall. This eventually leads to much stronger stratification (by a factor of 2 to 10) across the boundary layer than in the quiescent fluid. This stable situation is sufficient to inhibit turbulent production near the wall and reorganize the boundary layer into a parallel shear flow. Mixing ceases and remains negligible for approximately 6-8 hours until the flow again returns upslope. It takes approximately 2 hours of upslope flow, for the specified physical parameters before the turbulence recommences in earnest. Similar behavior is suggested by the field data from HOME and a related asymmetry between induced mixing on flood and ebb tides in estuaries has been observed previously, e.g., Simpson et al., 1990.
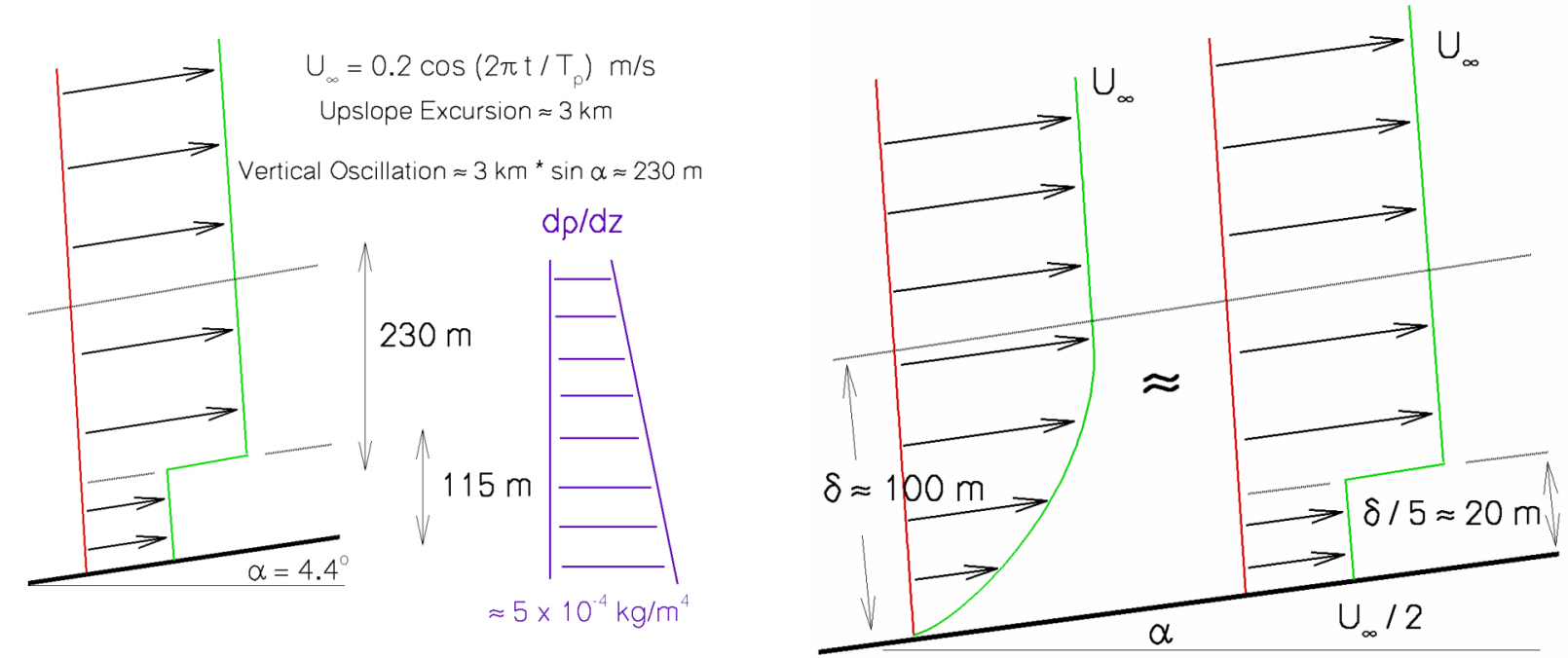

Figure 2. Illustrative sketch of boundary layer production of buoyancy flux. Left panel shows a typical boundary layer profile that could be idealized as a thinner layer of fluid moving at about half the velocity of the free stream. For the tidal flow used here with an upslope excursion of $3 \mathrm{~km}$, therefore the free stream would move vertically $230 \mathrm{~m}$, while the slower moving layer would only transverse $115 \mathrm{~m}$. This would allow a layer of lighter fluid to move 115 meters above the heavier bottom retarded fluid in the boundary layer.

We repeated the simulations with different values of the bottom slope, Reynolds number, and Prandtl number. The distance from the boundary that the turbulence reached was less for the other slopes. For the $9^{\circ}$ slope, the mixing begins earlier in the cycle and persists for longer duration but the plumes do not extend as far from the boundary. This is consistent with the interpretation (below) that there is greater buoyancy flux in this case and it is released sooner because the vertical distance traversed by the free stream velocity is twice as large as for the $4.4^{\circ}$ case. No turbulence is produced in the flat 
bottom case indicating that the release of tidal potential energy, rather than interactions caused by the tidal kinetic energy alone are responsible for the mixing.

The boundary layer is observed to become strongly restratified between mixing cycles. The amount of tidal potential energy that is released to turbulent mixing in the benthic boundary layer on the slope is directly related to the boundary layer thickness, or more precisely to the momentum thickness, $\theta$,

defined as $\theta(t)=\int_{0}^{\delta} \frac{u}{U_{\infty}}\left(1-\frac{u}{U_{\infty}}\right) d z$. Here, $u(z)$ is the horizontally averaged instantaneous upslope velocity profile and $\delta$ is the boundary layer thickness, above which the free stream velocity is within $1 \%$ of $U_{\infty}$ For a steady turbulent boundary layer in an unstratified environment, over a flat plate, it is common that the momentum thickness is approximately $10 \%$ of the boundary layer thickness. A laminar boundary layer has $\theta \cong 0.15 \delta$. It is unclear what the relationship between $\theta$ and $\delta$ in the unsteady flow over a rough wall in the benthic boundary layer in a stratified fluid. Measurements from the simulations were typically between 7 and $20 \%$ of $\delta$ depending on the phase of the tide.

The flux of available potential energy produced by the process of heavier upslope fluid moving faster on the slope than lighter boundary layer fluid is

$\frac{d P E_{A}}{d t}=\int_{V} \rho g w d V=A_{x y} g \int_{0}^{\theta} \frac{\partial \bar{\rho}}{\partial z} z U_{\infty}(t) \sin (\alpha) d z=A_{x y} g \frac{\theta^{2}}{2} U_{\infty} \frac{\partial \bar{\rho}}{\partial z}(t) \sin (\alpha)$ where potential energy is

defined (Winters et al, 1995) as $P E=g \int_{V} \rho z d V$. From this we could estimate the total mixing produced by this process in the deep ocean over a planform area $\left(A_{x y}\right)$ as Mixing $\approx R_{f} \beta A_{x y} g \frac{\theta^{2}}{2} \frac{U_{M}}{3} \frac{\partial \bar{\rho}}{\partial z} \alpha$ where $\beta$ is the factor accounting for the angle between the principle axis of the barotropic tide and the upslope direction, the small angle approximation is used for $\sin (\beta)$, and the factor $U_{M} / 3$ accounts for the portion of the wave period when the tide is going upslope and that the average value of $U_{\infty}$ is less than the maximum velocity $U_{M}$. The greatest variability in the formula will be caused by the value of $\theta$, which we estimate to be in the range of $4-40 \mathrm{~m}$ for different situations, and may be strongly dependent on the bottom roughness, and on $\frac{\partial \bar{\rho}}{\partial z}$ which changes by approximately 2 orders of magnitude across the ocean depth. Taking some ballpark numbers for these quantities, given the large value of $A_{x y}$, it is simple to show that the release of tidal potential energy by this process could produce in the range of $0.1-1 \mathrm{TW}$ of mixing in the ocean (cf. Munk and Wunsch, 1998). Improved areal estimates, utilizing methods of Egbert and Ray (2001) are a focus of our ongoing work.

\section{IMPACT/APPLICATIONS}

Improved understanding of deep ocean mixing has potential benefits for society in improved models of global climate change and turbulence in the ocean is relevant to ocean acoustics.

\section{TRANSITIONS}

The project is in the initial stages. We have developed the model and are testing the sensitivity of the oceanic response to environmental forcing conditions. 


\section{RELATED PROJECTS}

The National Science Foundation is supporting a large multi-institutional effort, led by Rob Pinkel at the University of California, San Diego, Scripps Institution of Oceanography, on the Hawaiian Ocean Mixing Experiment. Levine is a participant in the HOME field study.

\section{REFERENCES}

Egbert, G.D. and R.D. Ray, 2001, Estimates of M2 tidal energy dissipation from TOPEX/Poseidon altimeter data, J. Geophys. Res., 106, 22475-22502.

Munk, W, and C. Wunsch: 1998: Abyssal recipes II: Energetics of tidal and wind mixing, Deep-Sea Research, 45, 1977-2010.

Simpson, J. H., J. Brown, J. Matthews, and G. Allen, 1990, Tidal straining, density currents and stirring in the control of estuarine stratification, Estuaries, 13, 125-132.

Slinn, D. N. and J. J. Riley, 1998a, A model for the simulation of turbulent boundary layers in an incompressible stratified flow, Journal of Computational Physics, 144, 550-602.

Winters, K. B., P. N. Lombard, J. J. Riley, E. A.D’Asaro, 1995, Available potential energy and mixing in density-stratified fluids, Journal of Fluid Mechanics, 289, 115-128.

\section{PUBLICATIONS}

D.N. Slinn and M. D. Levine, 2003. Modeling internal tides and mixing over ocean ridges, HOME Analysis, Aha Hulikoa Hawaiian Winter Workshop, (P. Muller editor), Hawaii Institute of Geophysics, 59-68. 